\title{
Role of Maintenance in Reducing Building Vulnerability to Extreme Events
}

\author{
Lam Pham, Ekambaram Palaneeswaran \\ Swinburne University of Technology, Victoria, Australia
}

\author{
Rodney Stewart \\ Griffith University, Gold Coast Campus, Australia
}

Contacting author: Ipham@swin.edu.au

\begin{abstract}
The paper is to assess contribution of maintenance toward reducing building vulnerability to extreme weather events such as high wind, wild fire and flood. The aims are to gather technical knowledge to develop policy recommendations and guidelines for practice in Australia. Reducing building vulnerability to extreme events is one way of improving building resilience that is partly under the control of the building owners/occupiers. The performance of buildings will decease overtime without effective maintenance and their vulnerabilities to extreme events will increase. What are the opportunities to reduce building vulnerability via maintenance is the key question. Lack of consideration for maintenance during the design phase and lack of proper as-built documentation at completion of construction are the two main deficiencies of the Australian building system. The paper reviews the impacts of weather events in Australia. Losses due to storms, cyclones, wildfires and floods accounted for $96 \%$ to total losses due to disasters. Emerging risks for Australia are due to climate change, changes to construction practice and the introduction of new construction products without appropriate control. Maintenance activities currently carried out in Australia include (i) maintenance of essential safety measures, (ii) maintenance for habitability and (iii) preventive maintenance for extreme events. Maintenance is considered as a post-construction activity and a responsibility for States and Territories governments. Opportunities for reducing building vulnerability vary with the types of events. For storms and cyclones, water penetration remains a recurring and costly issue. For floods, the opportunities for the owners/occupiers are mainly in preparation of the buildings before the floods and subsequent clean up and repairs. For wildfires, the main opportunity is in reducing the risk of ignition due to embers action with appropriate maintenance measures for the buildings and surrounding areas. The main recommendation of the research is to establish a building maintenance manual for each building with prescribed information including (i) as-built construction details relevant to maintenance, (ii) required preventive maintenance checklist.
\end{abstract}

Keywords: buildings; extreme events; maintenance; facility management; wildfire; flood; storm 


\section{Introduction}

Improving building resilience under extreme events is a complex task. It involves (i) the assessment of the natures and the impacts of the events, (ii) the vulnerabilities of the buildings and their occupants and (iii) the financial and technical capabilities of the region. Reducing building vulnerability to extreme events is one way of improving building resilience that is partly under the control of the building owners/occupiers. Maintenance is defined as all activities taken while the buildings are in use to keep the building performance at a level acceptable to the users including periodic inspection, repair, replace and retrofit (upgrading of existing buildings).

This paper presents the results of an Australian project assessing the contributions of maintenance in reducing the vulnerability of the Australian building stock to extreme events [1]. It includes: (i) impacts of extreme weather events in Australia, (ii) Australian building maintenance practice, (iii) opportunities and feasibilities to reduce vulnerability.

The project was focussed on existing public building stock. The extreme events were limited to severe storm, flood, cyclone and wildfire. Its recommendations include general recommendations applicable to all buildings and specific recommendations for wildfire, flood and cyclone.

\section{Impacts of weather events in Australia}

The first major effort to collect Australian loss data was by Bureau of Transport Economics in 2001 [2] for the period 1967-1999 (32 years). This was updated in 2016 [3], extended the data to 2013 (46 years).

The total yearly average national loss from extreme events over 46 year period is $\$ 3.65$ billions (2013 Australian dollars). Loss analysis by States and Territories (S\&T) is presented in Fig. 1 and by event types in Fig. 2. It is observed that:

(i) total reported loss is more than twice the insured loss - this is probably because public building assets are generally not insured; (ii) there is an increase in losses from wildfire, which is a significant change from the earlier report;

(iii) there is no evidence of impacts of planning and building regulation on losses - there were considerable changes in these areas for the time reference periods.

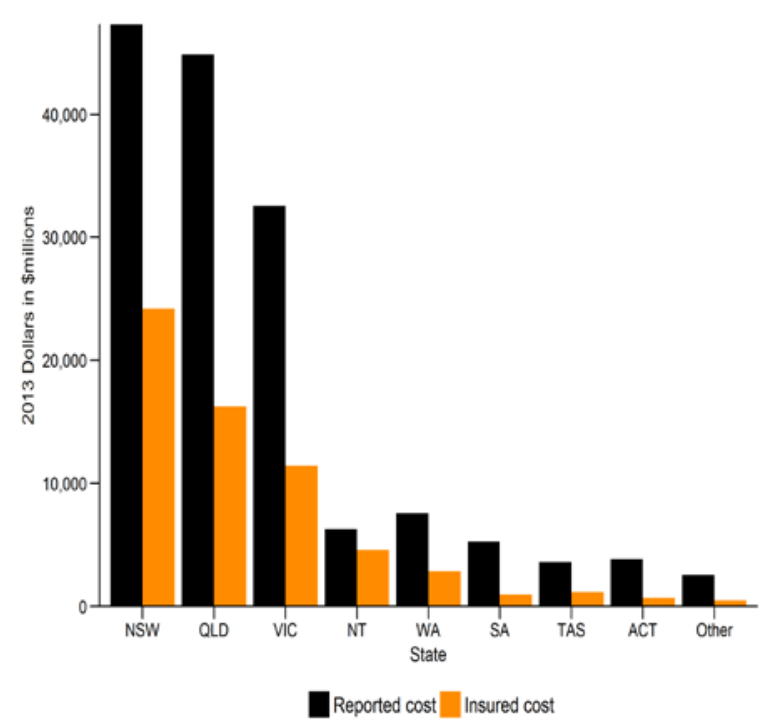

Figure 1. Losses by States and Territories

Table 1 presents average losses by States and Territories and types of event as percentage of total national loss. It is noted:

(i) losses due to storms, cyclone, wildfire and flood accounted for $96 \%$ of total loss (earthquake not included)

(ii) Queensland (QLD), New South Wales (NSW) and Victoria (VIC) suffered the most losses, totalling $80 \%$ of the national losses.

(iii) Different regions suffered from different types of events: storm losses are major item for NSW, flood and cyclone for QLD, bushfire and storm for VIC.

Distribution of the events with the magnitude of the losses is presented in Table 2 where it is seen that about $25 \%$ of the events cost more than $\$ 500$ millions per events and $50 \%$ of the events cost more than $\$ 100$ millions each. 


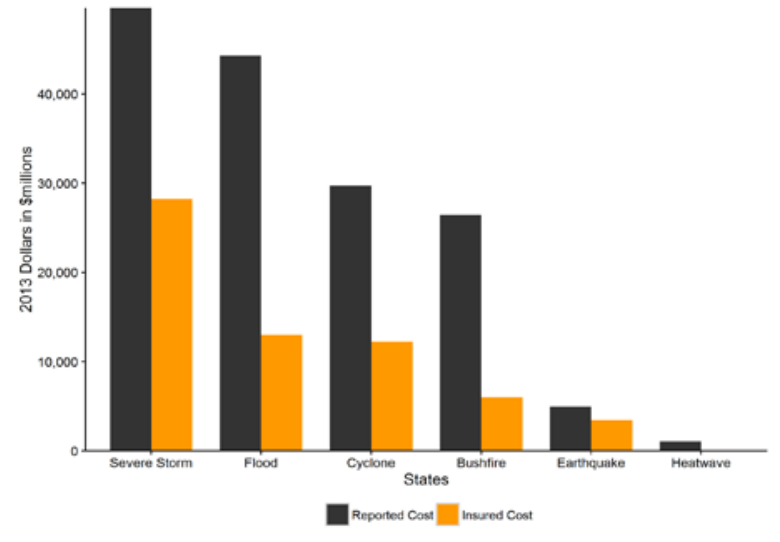

Figure 2. Losses by event types

Table 1. Average losses as percentage of national loss (values in \%)

\begin{tabular}{cccccc} 
& Wildfire & Flood & Cyclone & Storm & Total \\
\hline VIC & 8.9 & 3.6 & 0 & 9.0 & 21.5 \\
\hline NSW & 1.8 & 7.2 & 0 & 16.8 & 25.8 \\
\hline SA & 1.2 & 1.6 & 0 & 0.4 & 3.2 \\
\hline WA & 0.4 & 0.1 & 2.7 & 1.2 & 4.5 \\
\hline QLD & 0.6 & 14.4 & 13.1 & 3.8 & 31.9 \\
\hline TAS & 1.9 & 0.4 & 0 & 0 & 2.3 \\
\hline NT & 0 & 0.8 & 3.2 & 0 & 4.0 \\
\hline ACT & 2.2 & 0.2 & 0 & 0.5 & 2.9 \\
\hline TOT & 17 & 28 & 19 & 32 & 96 \\
\hline
\end{tabular}

Table 2. Distribution of losses with number of events

\begin{tabular}{ccccccc}
\hline $\begin{array}{c}\$ \\
\left(10^{6}\right)\end{array}$ & $\mathbf{1 0}$ & $\mathbf{1 0}-$ & $\mathbf{5 0}-$ & $\mathbf{1 0 0}$ & $\mathbf{1 5 0}$ & $>$ \\
\hline No & 4 & 59 & 55 & $\mathbf{- 1 5 0}$ & $\mathbf{- 5 0 0}$ & $\mathbf{5 0 0}$ \\
\hline CDF & 0.02 & 0.23 & 0.40 & 0.51 & 0.76 & 1 \\
\hline
\end{tabular}

\section{Australian emerging risks}

New risks to building infrastructure may result from changes to construction practice, new products, and climate change.

Current research on climate change indicates that extreme weather events are likely to be more intense. However, available data are not adequate to quantify the changes in terms of frequency and intensity [8]. In Australia, the effect of heavy rainfall after long-term draught, for example, resulted footing and foundation damage from ground swelling [9].

Changes in construction practice that restricted the movement of moisture and water resulted in major damage to buildings such as the leaky house syndrome in New Zealand and Canada [10] and major condensation problems in living space due to tight sealing requirements for energy efficiency in Australia [11].

The use of new products for cladding contributed to some major fires in UK and Australia [12]

Regular maintenance inspection could be used to detect some of these emerging risks.

\section{Australian practice}

\subsection{Types of maintenance}

There are three types of maintenance being currently carried out in Australia:

(a) Maintenance of essential safety measures these are mandatory for all States \& Territories (S\&T) in Australia. All S\&T have developed guidelines for the maintenance of essential safety measures such as fire-fighting services and equipment, lifts, lighting etc. [4].

(b) Maintenance for habitability (aesthetic and comfort) - these are generally carried out by the building owners or facility managers. There is no mandatory requirement for this type of maintenance.

(c) Preventive Maintenance - this type of maintenance is often carried out to prepare for an extreme event, i.e. part of emergency service response. They are often of short term nature, no 
consideration is given to long term effects generally.

\subsection{Maintenance in policy and regulation}

The major national document the National Construction Code (NCC) has no provision on maintenance. Maintenance is considered as a postconstruction activity and a responsibility for States \& Territories.

There is a national guideline for durability issued by the Australian Building Codes Board (ABCB) [5], where a maintenance schedule is considered as a key component for the description of durability performance. There are no durability requirements in the NCC, however its referenced documents for design do provide guidance for durability.

A recent report on the effectiveness of compliance and enforcement of Australian building regulatory system [6] was quite critical of its performance. Its key findings include serious compliance failures, incompetent practitioners, inadequate documentation and weak oversight. For post construction management, it recommends a manual for each building required to be provided and to have as-built construction documentation and maintenance requirements as key components of the manual.

\subsection{Resilience in policy and regulation}

In 2011, Council of Australian Governments (COAG) introduced a National Strategy for Disaster Resilience. It recommended that 'building standards and their implementation are regularly reviewed to ensure that they are appropriate for the risk environment' [7].

Extreme events currently covered by the NCC, in terms of design requirements, include: cyclone and high wind, intense rain, wildfire, snow and flood. The design requirements are prescribed in terms of design events with specified annual probability of exceedance. These specifications are under constant review particularly after major extreme events and the results of research. The current $A B C B$ position is that the prescribed levels are adequate for the anticipated climate for the next 50 years associated with a low emission scenario. It is important to note that the NCC prime concern is life safety. A level of property protection may exist as the consequence and may not extend to the building content. Extreme events not covered by the NCC include: hail, storm tide, heat wave, drought. The $A B C B$ acknowledged that 'maintenance is a critical factor' for buildings designed to current standard to withstand future extreme events [8].

\section{Reducing building vulnerability}

\subsection{General}

To identify opportunities for reducing building vulnerability, it is necessary to obtain a better understanding of the risk exposure, the resistance of buildings and the hazard characteristics as outlined in the Sendai Framework for Disaster Risk Reduction [13].

With respect to the risk exposure, the Australian practice does not consider (i) the simultaneous effects of multiple hazards, (ii) the relationship between the buildings and the supporting infrastructures and (iii) the density of the buildings in a region.

The vulnerability of the buildings is dependent on a number of factors such as the age of the building, the type of construction, the amount of maintenance and the nature of the hazard.

Maintenance is part of design for durability. A maintenance schedule should be provided as part of the final design documentation. Consideration of maintenance during the design stage has many benefits: (i) It could allow different strategies for maintenance to be considered as part of service life planning (e.g. replacement of parts and the frequency of inspection) and (ii) It could facilitate maintenance action by providing safe and easy access to components that required maintenance.

A maintenance manual for each building should be made available for the people responsible for its maintenance. Each building is exposed to different kind and level of hazards that will require different kinds of maintenance actions. This is particularly relevant to public assets where personnel changes make it difficult to track how decisions are made and systems are maintained over the service life of the building. As-built documentation particularly 
for items that are affected or required for maintenance should be made available [1].

Other opportunities to improve resilience for specific weather events are outlined in subsequent sections.

\subsection{Storms and cyclones}

In Australia, the vulnerability of buildings under high wind (storms and cyclones) is dependent mainly on the ages of the buildings. There was a considerable tightening of the building construction practice for high wind around 1980. Consequently, there were considerable less damage caused by cyclones for post-1980 buildings [14].

Research conducted at Griffith University indicated that water penetration caused by wind-driven rain remains a recurring and costly issue. The situation can be improved with better installation and repair practice [1].

The Cyclone Testing Station (CTS), Townsville has identified the vulnerable elements of a building in a cyclone: roof connections, gable end walls, windows and doors, garage doors, roof eaves and attachments [15]. CTS is also working on a software package for condition assessment to improve building vulnerability [16].

As most cyclone resisting features are hidden from view, opportunities for reducing vulnerability is to 'build back better' [17]. This is often suggested but not often practiced in Australia because of lack of pre-planning.

\subsection{Floods}

Floods in Australia are caused mainly by heavy rainfall resulting in both riverine and flash flooding. Flash floods are localized events caused by the drainage system inability to cope with intense bursts of rainfall. Similarly, riverine floods result when the watercourses are unable to cope with the excess water [18]. Storm surge accompanying a cyclone is another likely cause of flooding. This could cause more damage to buildings than the cyclone itself [14].

Floods can cause damage to buildings because of the effect of moisture on construction materials and water actions such as flow speed and buoyancy. The indirect effects of floods are far more significant such as isolation of critical facilities and disruption of services such as electricity, communication, water, sewage etc. Flash floods are more serious risk to vehicles than buildings.

Maintenance for floods therefore relates to the maintenance of the flood plain management, the maintenance of the drainage system, flood emergency and flood warning systems. These are responsibilities of governments. Opportunities for the building owners to minimise damages are in the preparation of the buildings before the floods and subsequent clean up and repairs.

Opportunity to 'build back better' [17] should be considered for frequently flooded areas.

\subsection{Wildfires}

The main parameters for wildfire hazard are weather, vegetation, and ground slope. In Australia, the level of hazard for a particular location is assessed in terms of Bushfire Attack Level (BAL), a measure of 'the severity of a building potential exposure to ember attack, radiant heat and direct flame contact' [19]. Buildings within the 'designated bushfire prone area' are required to be designed in accordance with its BAL rating. Distance of a building to the bush is an important parameter. Indicative distance for $80 \%$ of all house losses is 100 metres and $90 \%$ of ignitions leading to building loss is by ember actions [20].

Maintenance has a key role in reducing the risk of ignition due to ember actions by either (i) removing combustibles from exposed elements around the building and (ii) preventing embers from entering and/or accumulating in the building cavities (roof, wall and under floor spaces). There are many guides to maintenance for wildfire in Australia [21].

\section{Conclusions}

This paper examines the role of maintenance in making buildings more resilient to extreme weather events: cyclones/storms, bushfires and floods, using technical knowledge to inform Australian policy makers and Australian practitioners. The paper reports on the impacts of weather events on Australian buildings, Australian 
policies and regulations relating to building maintenance and resilience. The paper identifies opportunities for improving resilience via maintenance within the Australian context. Lack of consideration for maintenance during the design phase and lack of proper as-built documentation at completion of construction are the two main deficiencies of the Australian building system. The recommendation is to establish a building maintenance manual for each building with prescribed information including (i) as-built construction details relevant to maintenance, (ii) required preventive maintenance checklist

\section{References}

[1] Pham L., Stewart R., and Palaneeswaran E. Resilient Buildings:Informing maintenance for long-term sustainability - Final Report Sustainable Built Environment National Research Centre (SBEnrc).

[2] Bureau of Transport Economics. Economic Cost of Natural Disasters in Australia, Report 103 Canberra 2001.

[3] Handmer, J., Ladds, M. and Magee, L. Disasater Losses from Natural Hazards in Australia, 1967-2013. Final Report updating the 20001 Australian Bureau of Transport Economics study on "The Economic Costs of Natural Disasters in Australia, RMIT University, Melbourne, Australia, 2016

[4] Victoria Building Commission. Essential Safety Measures Maintenance Manual

[5] Australian Building Codes Board. Durability in Buildings. $A B C B, 2006$

[6] Shergold, P. and Weir, B. Building Confidence - Improving the effectiveness of compliance and enforcement systems for building construction industry across Australia-Canberra, February 2018

[7] Council of Australian Governments National Strategy for Disaster Resilience: Building Our Nation Resilience to Disasters, Canberra, 2012

[8] Australian Building Codes Board. Resilience of buildings to extreme events, ABCB, 2014.
[9] Victorian Building Authority Minimising foundation movement and damage to your house Housing Engineering Design \& Research Association (HEDRA) August 2015

[10] New Zealand Government Leaky homes Ministry of Business, Innovation and Employment 2017

[11] Australian Building Codes Board Condensation in Buildings. ABCB 2014

[12] Baillieu, T. and Thwaites, J. Victorian Cladding Taskforce - Interim report Victoria Department of Environment, land, Water and Planning, 2017

[13] UNISDR Sendai Framework for Disaster Risk Reduction 2015-2030. United Nations Office for Disaster Risk Reduction, 2015

[14] Cyclone Testing Station, Tropical Cyclone Yasi Structural damage to buildings, Technical Report 57, James Cook University, 2011.

[15] Cyclone Testing Station, Is your house prepared for a cyclone-advice for the home owner, CTS Brochure, 2008.

[16] Cyclone Testing Station, Guidance Document for Resilient Self-assessment Tool (ResiST), James Cook University, 2008.

[17] UNISDR. Build Back Better - in recovery, rehabilitation and reconstruction. United Nations Office for Disaster Risk Reduction.

[18] SCARM, Floodplain management in Australia- Best Practice Principles and Guidelines, Report No 73, CSIRO Publishing, Collingwood, Victoria, 2000.

[19] AS 3959 - 2009: Construction of buildings in bushfire prone areas (Incorporating Amendment Nos 1, 2 and 3), Standards Australia, Sydney, 2009.

[20] Ahern, A., and Chladil, M. How far do bushfires penetrate urban areas? Proc. Australian Disaster Conf. 1999, Disaster Prevention for the 21st Century. Canberra: Emergency Management Australia, 1999

[21] HB 330 - 2009 Living in bushfire-prone areas Standards Australia, Sydney, 2009 